\title{
ESTUDO SOBRE O CICLO NATURAL DO ABACAXIZEIRO 'CAYENNE' NO PLANALTO PAULISTA ${ }^{(1)}$
}

ELOYS JACSKMOLLEY GIACOMELLI (2), Seção de Fruticultura Tropical, Instituto Agronômico, CLAUDE PY e PIERRE LOSSOIS, Centre de Recherches de Montpellier, Institut de Recherches sur les Fruits et Agrumes (3)

\section{RESUMO}

Com o objetivo de obter subsídios para o escalonamento racional das épocas de produção de abacaxi 'Cayenne' no planalto paulista, foi realizado um experimento de campo sobre o ciclo natural da planta em função de plantios trimestrais de mudas dos tipos coroa, filhote e rebentão de 300 a $400 \mathrm{~g}$, bem como do tipo rebentão de 700 a $800 \mathrm{~g}$. Constatou-se a existência de dois grandes periodos de diferenciaçāo floral espontânea: o principal, em abril-maio (meados de outono), e o secundário, em novembro-dezembro (entre meados da primavera e início do verão). Os resultados obtidos serviram de base para a elaboração de umi quadro indicativo das melhores mudas e das respectivás melhores épocas de plantio e indução química da diferenciação floral para çiferentes épocas de produção desejadas, sem uso de irrigação.

\section{INTRODUÇĀO}

Dentro de cada zona abacaxícola, é de grande importância prática o conhecimento do ciclo natural do cultivar empregado, em função de diferentes épocas de plantio, com diferentes tipos e pesos de mudas, a fim de que se possa escalonar racionalmente as épocas de produção.

(1) Recebido para publicação a 19 de setembro de 1983.

(2) Trabalhos de campo executados com bolsa de suplementação do CNPq.

(3) IRFA, B. P. $5035-34032$ Montpellier Cedex, France. 
No início da década passada, foi realizado um experimento sobre o ciclo natural do abacaxizeiro 'Cayenne' no planalto paulista. A maior parte dos resultados obtidos está sendo aqui publicada pela primeira vez, embora já bastante utilizados pela Seção de Fruticultura Tropical do Instituto Agronômico, para o planejamento de pesquisas abacaxicolas, bem como para orientação de consulentes, sobretudo abacaxicultores, interessados no domínio das épocas de produçāo de abacaxi.

O objetivo deste trabalho é apresentar e discutir os I,rincipais dados inéditos daquele experimento, juntamente com aqueles já publicados, não apenas para referências futuras, mas também com o propósito de estimular o desenvolvimento de outras pesquisas no Brasil sobre o ciclo natural do abacaxizeiro, na realidade ainda muito pouco estudado por nossos pesquisadores.

A matéria publicada, que abrange apenas os plantios com filhotes de 300 a $400 \mathrm{~g}$, fez parte de uma tese de doutoramento (1) e, recentemente, foi reproduzida numa obra didática sobre o abacaxi (2).

Os plantios foram feitos nas mesmas épocas de um experimento vizinho que envolveu quatro diferentes épocas de produçäo do cultivar Cayenne, com indução química da diferenciação floral, doze meses após o plantio com filhotes pesando 300 a $400 \mathrm{~g}$ (3).

\section{MATERIAL E MÉTODOS}

O experimento foi realizado no município de Pitangueiras (SP), zona de Bebedouro, na Fazenda Capim Verde, então pertencente ao Sr. Edmond Van Parys, adiantado fruticultor que, há muitos anos, vem apoiando o desenvolvimento de pesquisas abacaxicolas no planalto paulista.

A área utilizada, anteriormente ocupada por uma plantação de maracujazeiro, que sucedera a uma pastagem natural, está situada dentro da principal zona citrícola do País, a $500 \mathrm{~m}$ de altitude.

Os dados climáticos e o comprimento dos dias relativos ao periodo de execução do experimento, que se encontram nas figuras $2,3,4$ e 5 (parte inferior), foram obtidos no Posto Meteorológico da Estação Experimental de Pindorama, do IAC, situado a $562 \mathrm{~m}$ de aititude, $21^{\circ} 10^{\prime} \mathrm{S}$. e $48^{\circ} 54^{\prime} \mathrm{W}$., a cerca de $50 \mathrm{~km}$ do local do experimento.

O solo empregado é um latossolo vermelho-escuro textura média, de acidez e fertilidade baixas.

O quadro 1 apresenta os resultados das análises química e granulométrica de uma amostra dos primeiros $20 \mathrm{~cm}$ de profundidade do solo do experimento, coletada antes da calagem e da primeira adubação. 
QUADRO 1. Resultados das análises química e granulométrica de uma amostra do solo do experimento, tomada dos primeiros $20 \mathrm{~cm}$ de profundidade, antes da calagem e aplicação de adubos

\begin{tabular}{|c|c|}
\hline Análises & Resultados \\
\hline Química (1) & $\begin{array}{l}\mathrm{pH}=6,20 \\
1,25 \% \text { de carbono } \\
0,03 \text { e.mg de } \mathrm{PO}^{3-} / 100 \mathrm{ml} \text { de T.F.S.A. (3) } \\
0,19 \text { e.mg de } \mathrm{K}^{+} / 100 \mathrm{ml} \text { de T.F.S.A. (3) } \\
2,20 \text { e.mg de } \mathrm{Ca}^{2}-\mathrm{Mg}^{2}+/ 1 \mathrm{COml} \text { de T.F.S.A. (3) } \\
0,00 \text { e.mg de } \mathrm{Al}^{2+} / 100 \mathrm{ml} \text { de T.F.S.A. (3) }\end{array}$ \\
\hline Granulométrica (") & $\begin{array}{l}25,0 \% \text { de argila } \\
3,7 \% \text { de limo } \\
44,2 \% \text { de areia fina } \\
27,1 \% \text { de areia grossa } \\
\text { Classificação textural: areno-barrenta }(4)\end{array}$ \\
\hline
\end{tabular}

(1) e (2) Efetuadas, respectivamente, pela Seção de Fertilidare do Solo e Seção de Pedologia do IAC. (3) Teores trocáveis em $100 \mathrm{ml}$ de terra fina seca ao ar. A extração do fósforo foi feita com $\mathrm{H}_{2} \mathrm{SO}_{4} 0,05 \mathrm{~N}$. (4) Segundo critério adotado pelo IAC.

Utilizou-se um delineamento experimental de blocos ao acaso com as parcelas subdivididas e cinco repetições, constando 0 experimento de quatro tratamentos ou épocas de plantio:

$$
\begin{aligned}
\text { Janeiro } & =27 / 01 / 1970 \text { (meados do período das chuvas) } \\
\text { Abril } & =28 / 04 / 1970 \text { (início do período das secas) } \\
\text { Julho } & =29 / 07 / 1970 \text { (meados do período das secas) } \\
\text { Outubro } & =27 / 10 / 1970 \text { (início do período das chuvas). }
\end{aligned}
$$

Por sua vez, cada época de plantio comportou os seguintes subtratamentos ou categorias de mudas:

$$
\begin{aligned}
& \mathrm{c}=\text { coroa de } 300-400 \mathrm{~g} ; \\
& \mathrm{f}=\text { filhote de } 300-400 \mathrm{~g} ; \\
& \mathrm{r}=\text { rebentão de } 300-400 \mathrm{~g} \\
& \mathrm{R}=\text { rebentão de } 700-800 \mathrm{~g}
\end{aligned}
$$

Cada parcela experimental constou de 176 plantas dispostas em quatro linhas duplas, sendo 80 o número total de plantas úteis, pois foram consideradas marginais as plantas das duas linhas duplas laterais e das extremidades das duas linhas duplas centrais.

Tanto as coroas como os filhotes (mudas do pedúnculo do abacaxi) e os rebentões (mudas do talo do abacaxizeiro) foram pesados após uma semana de cura ao sol, com a base voltada para cima. 
Antes do plantio, as mudas ficaram três minutos imersas numa calda contendo $0,06 \%$ de diazinom e $0,2 \%$ de ortodifolatam, como medida preventiva contra o ataque por pragas e doenças.

O preparo do solo foi executado uma semana antes do plantio, consistindo numa aração e três gradeações, a última delas para incorporação de calcário dolomítico (como fonte de magnésio), superfosfato simples e heptacloro pó molhável a $40 \%$, respectivamente nas quaritidades de 50 , 50 e $2 \mathrm{~g}$ por metro quadrado.

O calcário utilizado continha $23,5 \%$ de $\mathrm{CaO}$ e $18,5 \%$ de $\mathrm{MgO}$.

O heptacloro foi incorporado com a finalidade de conibate a formigas que vivem normalmente em simbiose com a cochonilha Dysmicoccus brevipes (Cockerell) Ferris.

Adotou-se o sistema de plantio em linhas duplas e o espaçamento de $90 \times 45 \times 30 \mathrm{~cm}$ (tendo sido de $30 \mathrm{~cm}$ a distância entre plantas na mesma linha e de $90 \mathrm{~cm}$ a mantida entre as linhas duplas), isto é, na base de 50.000 plantas por hectare (não se considerando as perdas com carreadores).

Após o plantio, com o propósito de assegurar bom estado nutricional às plantas, efetuaram-se adubações bimestrais com uréia e sulfato de potássio, iniciando quando os abacaxizeiros estavam com um mês de idade e prosseguindo durante todo o transcorrer do experimento: os dois adubos foram aplicados nas axilas das folhas mais velhas das plantas, na base de $0,8 \mathrm{~g}$ de $\mathrm{N}$ e $1,2 \mathrm{~g}$ de $\mathrm{K}$ por planta, por adubação.

Para o controle das ervas más, realizaram-se duas aplicações de diurom, na base de $3 \mathrm{~kg}$ por hectare, por aplicação: a primeira delas logo após o plantio e, a outra, apenas entre as linhas duplas (caminhos), seis meses mais tarde. Além disso, executaram-se capinas manuais conn enxada.

Os tratamentos fitossanitários pós-plantio consistiram unicamente em pulverizaçōes contra a broca-do-fruto, Thecla basilides (Geyer), no período compreendido entre a emissão floral e cerca de quatro semanas após o término da fase de florescimento.

Não se empregaram irrigações.

O desenvolvimento vegetativo das plantas foi avaliado pela evolução da massa foliar teórica, de acordo com o método de PY \& LOSSOIS (4), tendo sido previstas avaliações aos 4, 6, 8, 10 e 12 meses - MFT4, MFT6, MFT8, MFT10 e MFT12 - utilizando-se as formulas:

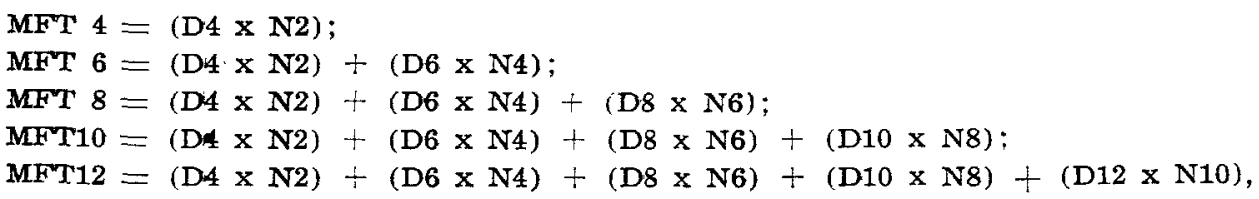


onde: D4, D6, D8, D10 e D12 correspondem, respectivamente, ao peso médio da folha $\mathrm{D}^{*}$, em gramas, quando as plantas estão com $4,6,8,10$ e 12 meses de idade, e N2, N4, N6, N8 e N10 representam, respectivamente, o número médio de folhas emitidas nos dois primeiros meses, entre o segundo e o quarto mês, entre o quarto e o sexto mês, entre o sexto e o oitavo mês, e entre o oitavo e o décimo mês.

Cada estimativa da massa foliar teórica envolveu o número máximo de 16 plantas úteis por subparcela experimental, ou seja, até $20 \%$ do número total de plantas úteis, excluindo-se a possibilidacie de utilização de uma mesma planta mais de uma vez e empregando-se apenas plantas que ainda não haviam emitido inflorescência (pois a produção de folhas $\mathrm{D}$ é interrompida pela diferenciação floral).

Por sua vez, as plantas úteis do experimento foram observadas semanalmente, para fins de acompanhamento da evolução das percentagens de emissão floral espontânea para a primeira frutificação.

Efetuou-se a colheita do primeiro fruto de cada uma das plantas úteis quando pelo menos cerca de $50 \%$ da casca se apresentava amarela, tendo então sido coletados dados de interesse prático para a elaboraçâo deste trabalho, a saber: a data de colheita; o peso do fruto com e sem a coroa; o número de filhotes e o número de rebentōes. Embora nos últimos plantios a colheita tivesse se prolongado até 1973, os dados colhidos depois de julho de 1972 não foram considerados para a elaboração das curvas representativas, pois não influíram nas tendências manifestadas.

\section{RESULTADOS E DISCUSSÃo}

\section{Crescimento da planta (Figura 1)}

O início do crescimento das plantas foi muito mais lento quando os plantios ocorreram em épocas frescas e secas (abril e julho). $\mathrm{Na}$ realjdade, de modo geral, esse crescimento diminuiu, aumentando nas épocas quentes e úmidas.

É também importante observar que, independenti da época de plantio, o desenvolvimento vegetativo foi sempre maior quando se empregaram rebentões de $700-800 \mathrm{~g}$. Entretanto, com tais mudas, as ava-

(*) Uma folha de abacaxizeiro do cultivar Cayenne leva cerca de quatro meses para atingir pleno desenvolvimento e máxima atividade fisiológica, recebendo então a designação de folha $D$, internacionalmente conhecida. a mais nova entre as folhas adultas da folhagem, podendo, porém, apresentar-se mais longa que aquelas produzidas anteriormente. Os bordos basais apresentam-se parajelos ou apenas ligeiramente divergentes, o que possiblita arrancá-la inteira, com certa facilidade, desde que pega na altura do terço basal e submetida a dois puxōes laterais vigorosos; isso não acontece com as folhas mais velhas, pois seus bordos basa is já se apresentam divergentes, sendo, portanto, maior a superfície de contacto com o talo da planta (2). 


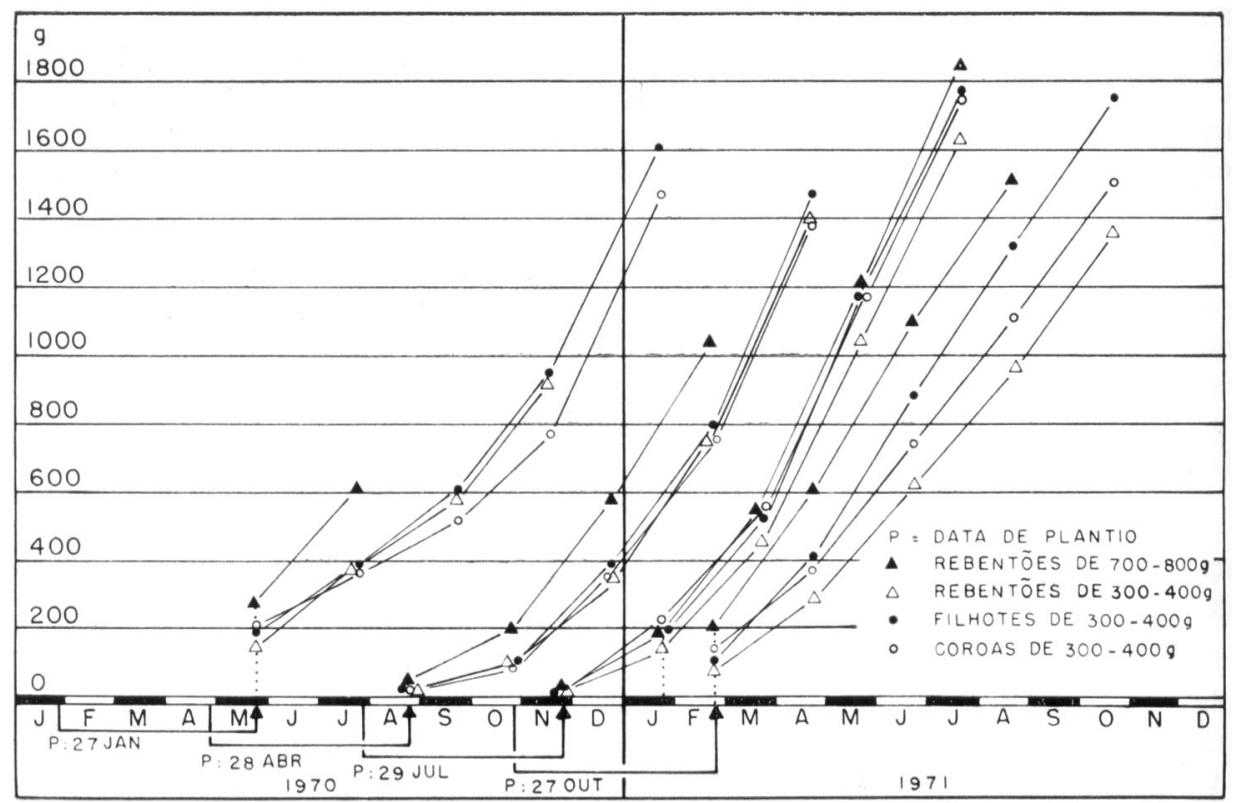

FIGURA 1. Evolução da massa foliar teórica das plantas, em função das datas de plantio, dos tipos e dos pesos das mudas empregadas.

liações da massa foliar teórica tiveram que ser interrompidas antes que as plantas atingissem 12 meses de idade (exceto no caso do plantio em julho), por causa da antecipação espontânea da diferenciação floral.

A dispersão das curvas correspondentes aos plantios de outubro é surpreendente, e talvez tenha ocorrido devido a algum fator não controlado, relacionado com a estocagem das mudas.

\section{Emergência das inflorescências (Figura 2)}

$\mathrm{O}$ peso das mudas por ocasião do plantio teve influência decisiva sobre o ciclo das plantas: com rebentão de 700-800g, o aparecimento da inflorescência no interior da roseta foliar ocorreu muito mais cedo do que com rebentão de $300-400 \mathrm{~g}$. Aliás, tal aparecimento sucede, em média, dois meses após a diferenciação floral e, de modo geral, a resposta aos fatores ambientes predisponentes é tanto mais lenta quanto mais jovem é a planta.

Tal resposta também variou com o tipo de muda utilizado para plantio: a coroa sempre se mostrou mais resistente $\grave{e}$ diferenciação floral, enquanto o rebentão foi o tipo mais sensível, situando-se $c$ filhote numa posição intermediária, exceto no caso do plantio em outubro, quando seu 


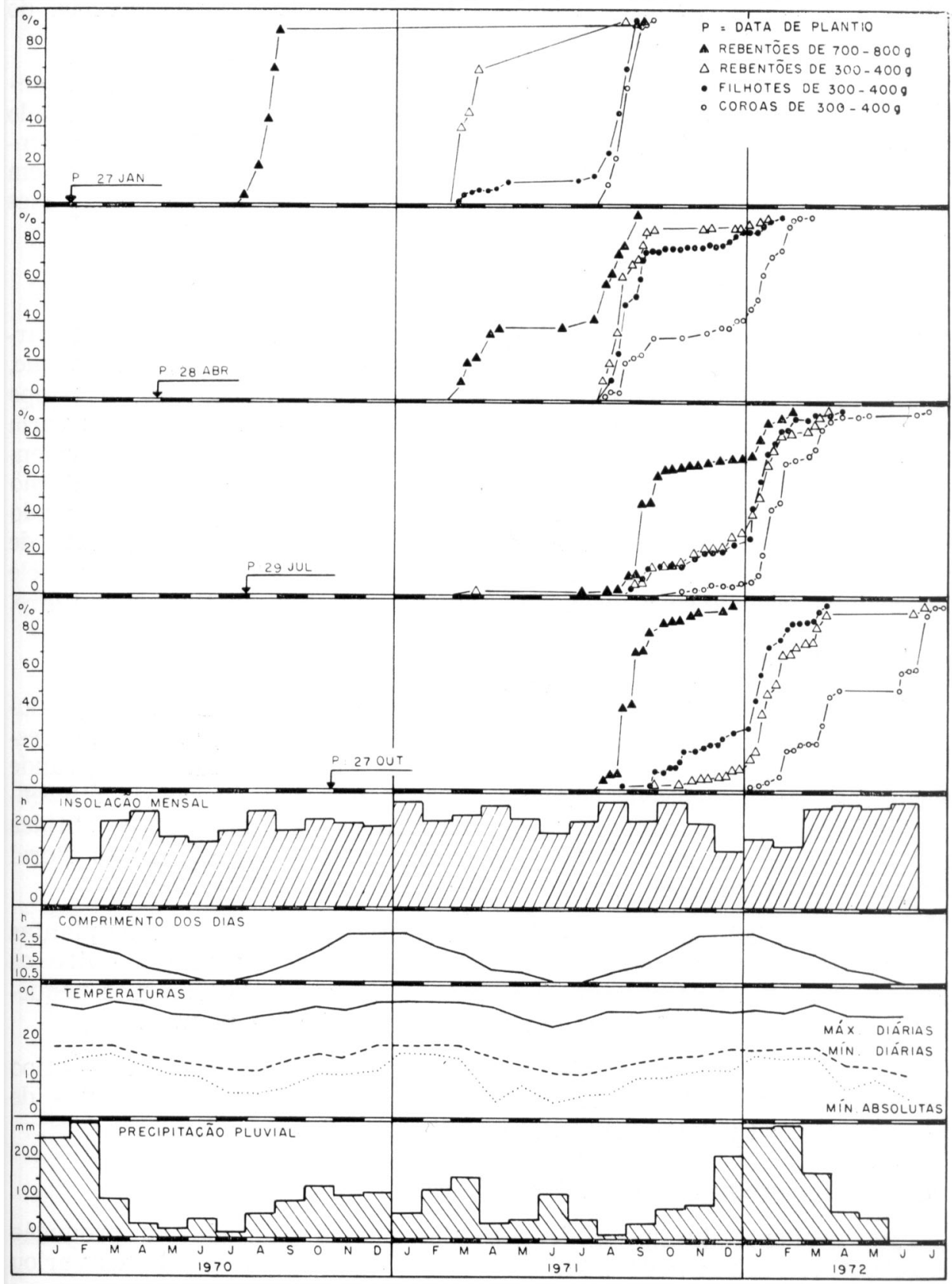

FIGURA 2. Evolução das percentagens mensais acumuladas referentes à emergência natural das inflorescências para a produção da primeira safra de frutos, em função das datas de plantio, dos tipos e dos pesos das mudas empregadas. 
emprego resultou em diferenciação floral ligeiramente mais precoce do que com utilização de rebentão de peso equivalente.

Constataram-se dois grandes períodos de diferenciação floral espontânea: o mais importante deles em abril-maio, fortemente relacionado com a diminuição do comprimento dos dias e com o abaixamento da tempertura nessa época do ano; o outro, secundário, manifestou-se em novembro-dezembro, provavelmente devido a vários fatores, entre eles um abaixamento da luminosidade.

\section{Repartição da colheita (Figura 3)}

Embora a repartição da colheita seja geralmente a imagem da repartiçāo da saída das inflorescências, é preciso atentar para $c$ fato de que, em zonas de estações climáticas marcantes, como Bebedcuro, o tempo compreendido entre a diferenciação floral e a maturação dos frutos varia sensivelmente de uma época do ano para outra, conforme ficou evidenciado em experimento ali conduzido concomitantemente com indução química da diferenciação floral, por GIACOMELLI et alii (3): quando efetuada em fins de abril, somente resultou em frutos maduros cerca de oits meses mais tarde, ou seja, após um mês e meio mais do que aquele despendido, fazendo-se o mesmo tratamento indutor em fins de outubro.

\section{Evolução do peso médio dos frutos (Figura 4)}

O plantio de rebentões de $700-800 \mathrm{~g}$ geralmente resultou na produção de frutos menores do que com rebentōes de 300-400g, spesar do crescimento mais rápido das plantas originárias daquelas mudas de grande porte, mas cujos níveis de crescimento, atingidos nas épocas da diferenciação floral, foram menores do que os alcançados pelas plantas obtidas a partir de mudas de 300-400g, pois, com estas, a diferenciação floral ocorreu mais tardiamente.

Por outro lado, quando a diferenciação floral ocorreu após as plantas terem atingido nível adequado de crescimento, as diferenças entre os pesos médios dos frutos resultantes passaram a ser relativamente pequenas, bem como os acréscimos em função da idade das plantas.

É também interessante observar que dos plantios com coroas - tipo de muda ainda muito pouco usado no Brasil - resultaram frutos de pesos médios situados entre os mais elevados do experimento.

\section{Evolução da produção de mudas (Figura 5)}

Independente do tipo e do peso das mudas plantadas, a produção de rebentões evoluiu pouco; por outro lado, a produção de filhotes variou consideravelmente em função de condições climáticas presentes no momento da diferenciação floral, tendo sido máxima quando tal diferenciação ocorreu em época fresca e seca, e mínima quando ela se manifestou em época quente e úmida. 


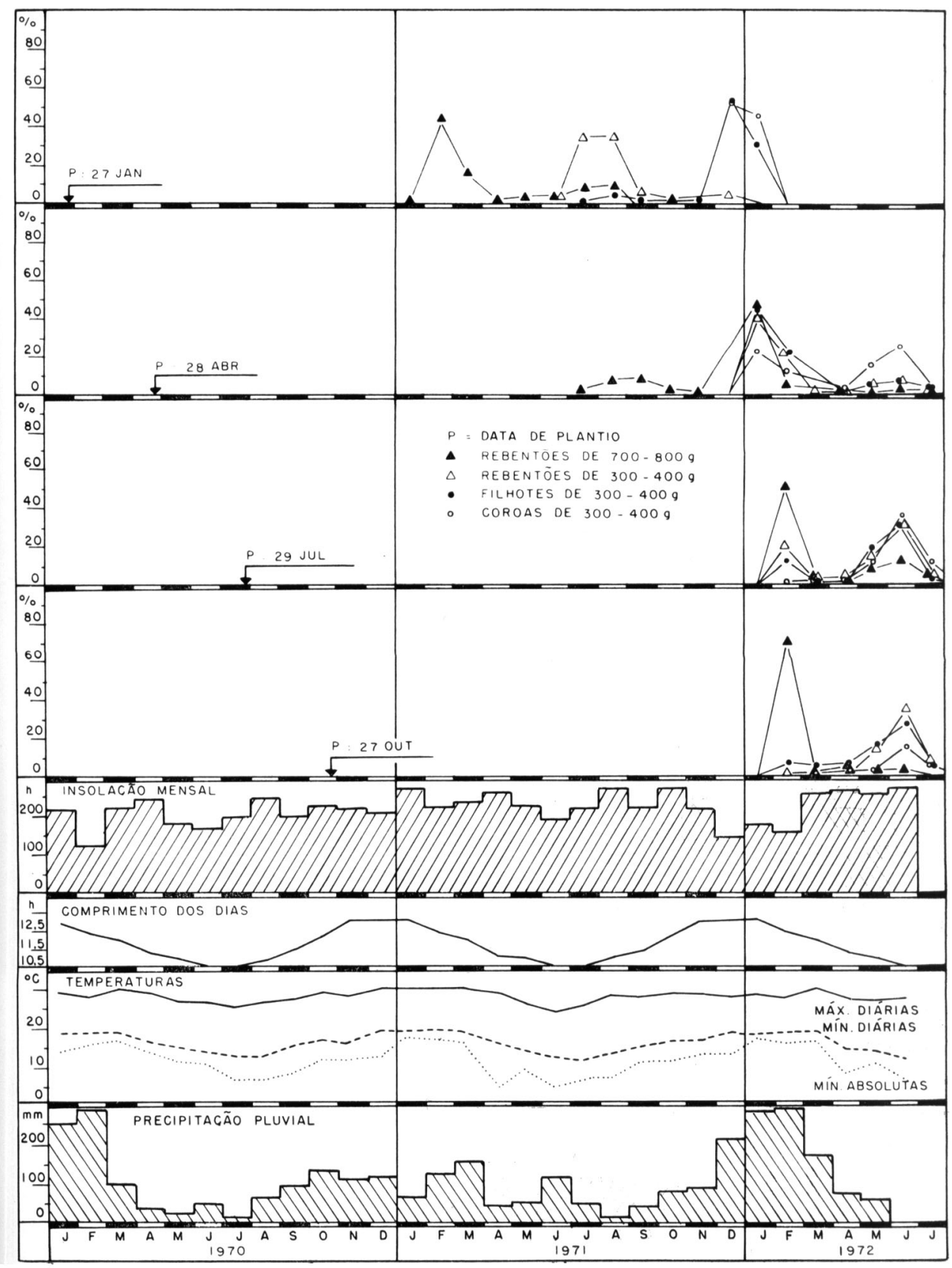

FIGURA 3. Repartição da colheita dos frutos da primeira safra, em função das datas de plantio, dos tipos e dos pesos das mudas empregadus: percentagens mensais de frutos maduros. 


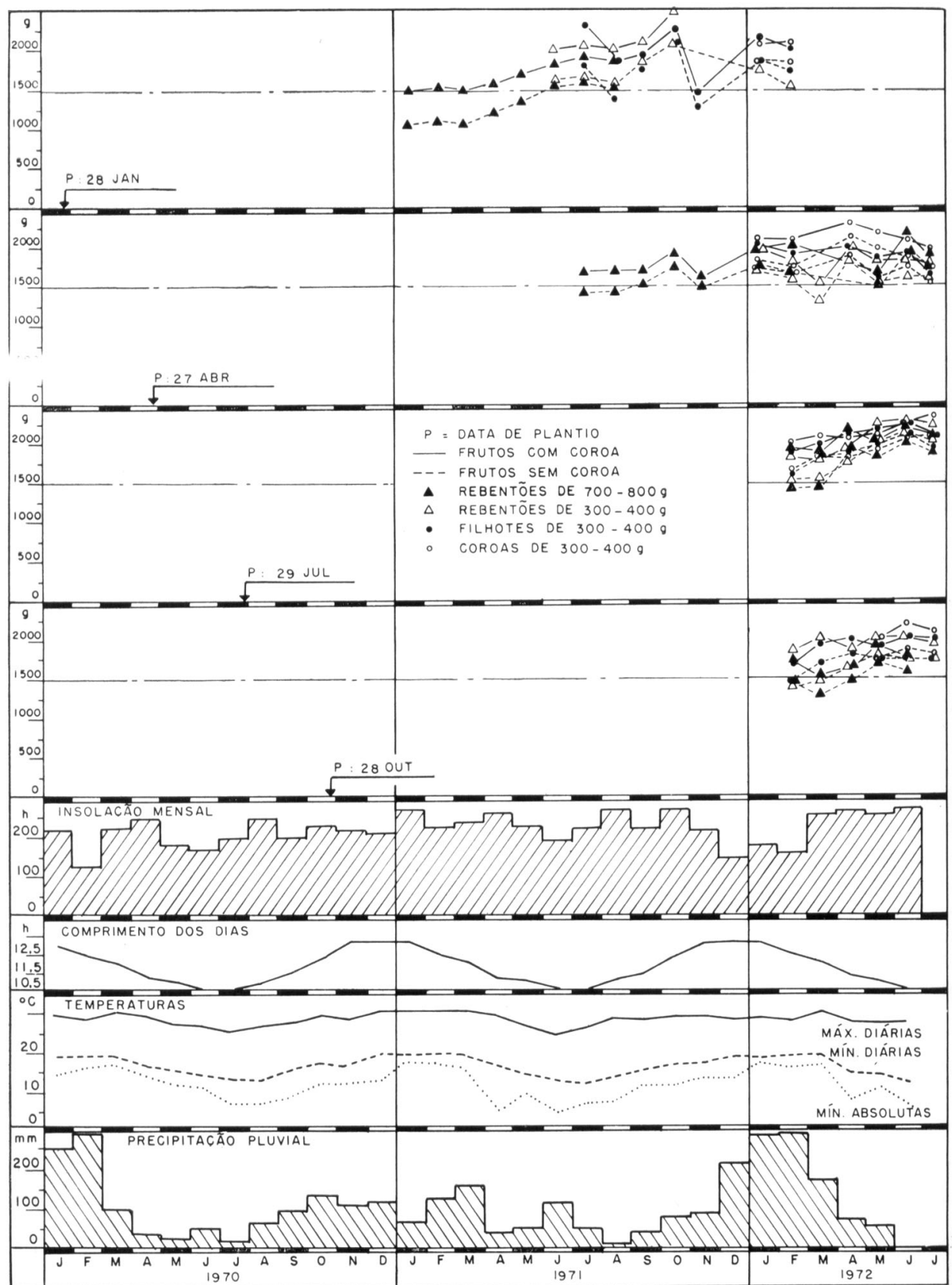

FIGURA 4. Evolução do peso médio dos frutos da primeira safra, em função das datas de plantio, dos tipos e dos pesos das mudas empregadas. 


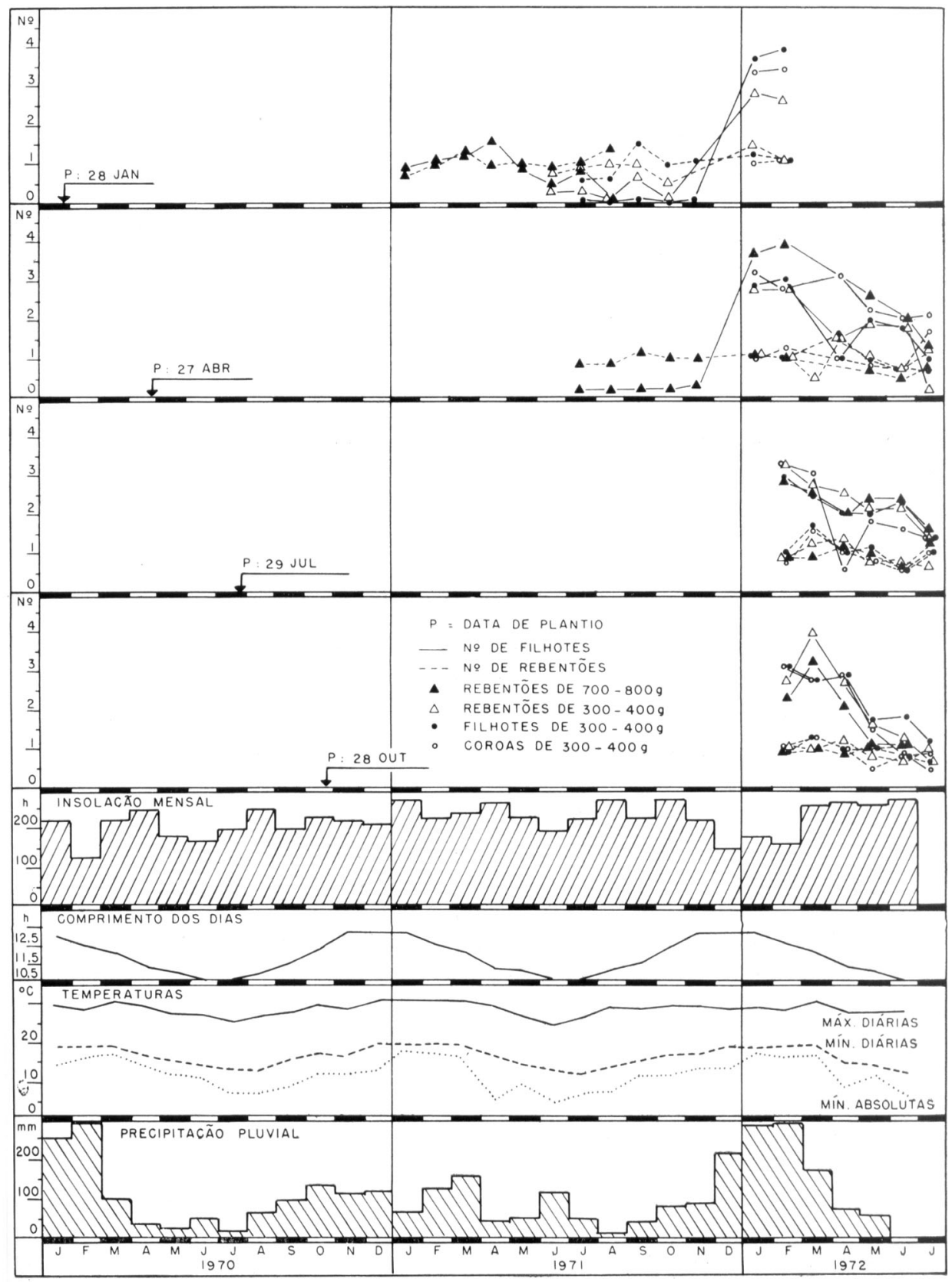

FIGURA 5. Evolução da produção de mudas na época da colheita dos frutos da primeira safra, em função das datas de plantio, dos tipos e dos pesos das mudas empregadas. 


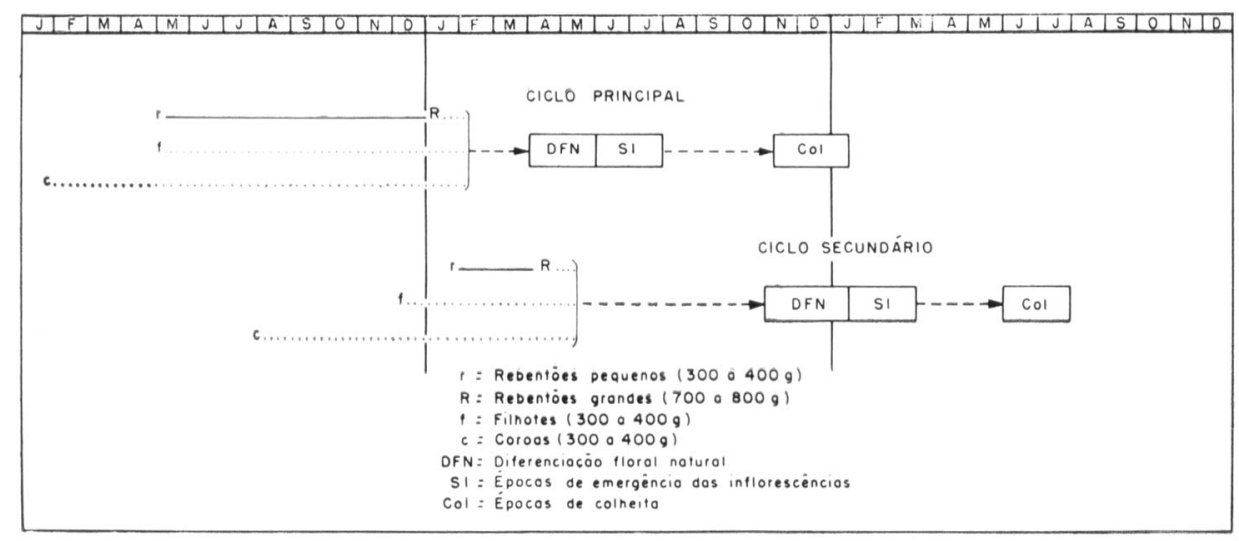

FIGURA 6. Representação esquemática dos dois principais ciclos naturais do abacaxizeiro 'Cayenne', na zona do experimento, sem emprego ce irrigação.

\section{Principais ciclos naturais (Figura 6)}

Os dados deste experimento revelaram a existência de dois grandes ciclos naturais do abacaxizeiro 'Cayenne' no planalto paulista: o principal, que é a base da produção no fim ou no início do ano, ou seja, na época da grande safra; e o secundário, em relação ao primeiro, mas também importante, pois é a base para a produção em meados do ano.

Efetuando o plantio em dezembro-fevereiro, pode-se cair num ou noutro desses ciclos, conforme o peso das mudas empregadas. $\bar{E}$ realmente nesses meses que ocorre o maior risco de as plantas diferenciarem as suas inflorescências em abril-maio, resultando disso a. produção de frutos pequenos, em plena época da grande safra, o que não é desejável para comercialização interna.

\section{Plano para produção o ano todo}

Os resultados aqui apresentados podem ser considerados relativamente seguros para aplicação prática, pois o experimento foi conduzido durante dois anos e meio, sob condições climáticas normais.

Com base nos resultados deste experimento e com apoio nos do experimento sobre diferentes épocas de produção com indução artificial da diferenciação floral, foi elaborado, para produção de abacaxi 'Cayenne' no planalto paulista durante todos os meses do ano, sern uso de irrigação, um plano, condensado na figura 7: para cada época de colheita desejada, estão indicadas as melhores mudas e as respectivas melhores épocas de plantio e indução química da diferenciação floral. 


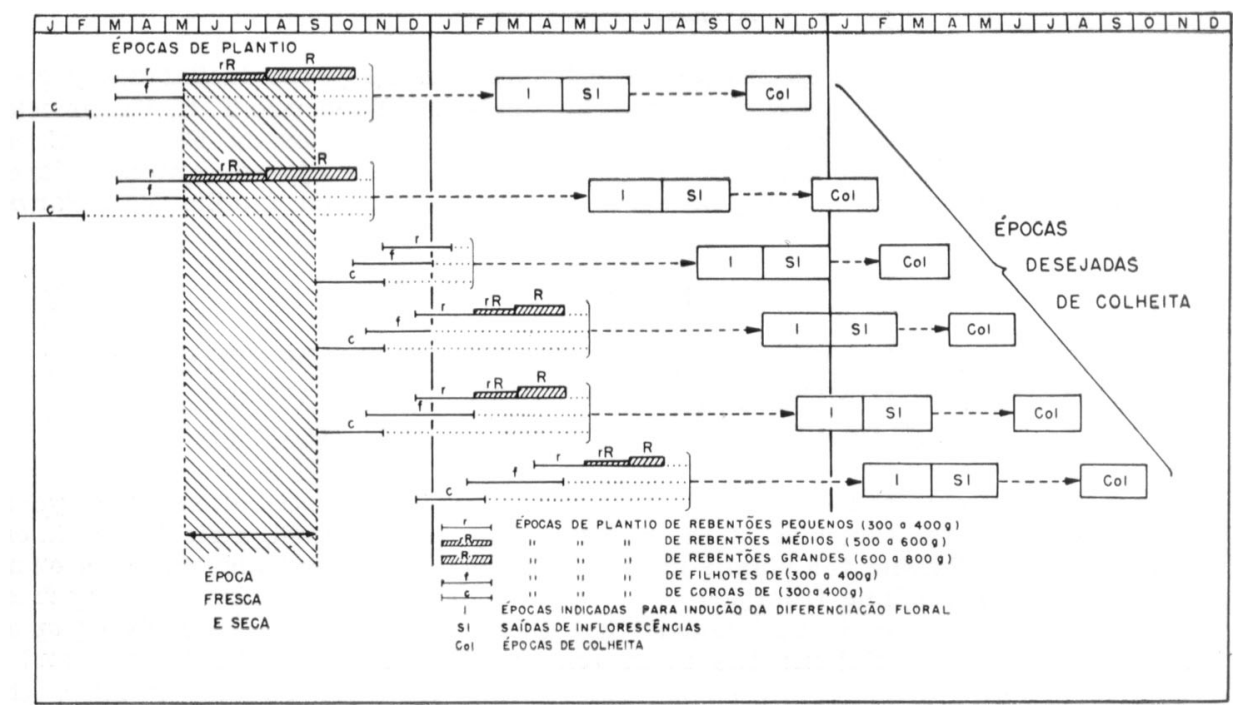

FIGURA 7. Plano para produção de abacaxi 'Cayenne' no planalto paulista, durante o ano todo, sem uso de irrigação: indicação das melhores mudas e das respectivas melhores épocas de plantio e indução artificial da diferenciação floral, para cada época de colheita desejada (primeira safra).

Dentro da época fresca e seca, não foi previsto o plantio de rebentões, filhotes e coroas de $300-400 \mathrm{~g}$, pelo fato de o desenvoivimento inicial ser demasiadamente lento.

Evidentemente, quando se desejar a produção de frutos de peso médio menor, deve-se induzir a diferenciação floral mais cedo: nesse caso, para que não haja diminuição do peso de fruto por área cultivada, pode-se plantar mais densamente.

\section{CONCLUSõES}

1. A diferenciação floral espontânea do abacaxizeiro 'Cayenne' no planalto paulista ocorre principalmente em abril-maio, mas também, con freqüência significativa, em novembro-dezembro e, ainda, em outros meses, em escala menos expressiva.

2. Sob condições ecológicas semelhantes àquelas presentes durante a execução deste experimento, é viável sua produção comercial o ano todo, sem emprego de irrigação.

3. Para o escalonamento racional das épocas de produção, faz-se, porém, necessária a indução artificial da diferenciação flcral, bem como o piantio em épocas e com mudas adequadas para cada época de produção desejada. 


\section{AGRADECIMENTOS}

Os autores agradecem a.o fruticultor Edmond Van Parys as facilidades proporcionadas para a realização do experimento; ao Eng-Agro Francisco T. C. Vasconcelos, a colaboração e incentivo durante a execução, e aos operários da Fazenda Capim Verde, a realização dos trabalhos de campo, especialmente ao jovem Antonio Clarete Bellotte, atual encarregado das plantações de abacaxizeiro da família van Parys.

\section{SUMMLAY \\ A STUDY OF THE NATURAL CYCLE OF THE CAYENNE PINEAPPLE PLANT IN THE TABLELAND OF THE STATE OF SÃO PAULO, BRAZIL}

In order to obtain basic information for a rational distribution of Cayenne pineapple crops in the tableland of the State of São Paulo, Brazil, a field experiment was carried out following the plant's natural cycle in a trimestral planting of crowns, slips, and suckers weighing from 300 to 400 grams, as well as suckers weighing from 700 to 800 grams. The results showed that there are two major periods of spontaneous floral differentiation: the main one in April/May (mid-autumn), and a secondary one in November/December (mid-spring to early summer). Also, the results allowed to draw up a table indicating the best types of planting material and the best planting seasons for each type, as well as the best time to use chemical induction of floral differentation for each desirable period of yielding without using irrigation.

\section{REFERENACIAS BIBLIOGRĀFICAS}

1. GIACOMELLI, E. J. Estudo sobre o comportamento do abacaxizeiro (Ananas comosus L.) Merril, cultivar Cayenne, na região de Bebedouro, Estado de São Paulo. Piracicaba, Escola Superior de Agricultura «Luiz de Queiroz», 1972. 37p. Tese. (Doutoramento)

2. - Expansão da abacaxicultura no Brasil. Campinas, Fundação Cargill, 1982. 79p.

3. _ - _ PY, C.; LOSSOIS, P. Estudo sobre épocas de produção para o abacaxizeiro Cayenne, no planalto paulista. In: CONGRESSO BRASILEIRO DE FRUTICULTURA, 5, Pelotas, 1979. Anais. Pelotas, Sociedade Brasileira de Fruticultura, 1979. v.2, p.499-511.

4. PY, C. \& LossoIs, P. Prévisions de récolte en culture d'ananas (II): étude de corrélations. Fruit, 17(2):75-87, 1962. 